\title{
QBEND10 for the diagnosis of myelodysplastic syndromes in routinely processed bone marrow biopsy specimens
}

\author{
H-P Horny, M Wehrmann, H U H Schlicker, A Eichstaedt, M R Clemens, \\ E Kaiserling
}

\begin{abstract}
Aim-The assessment of the value of the antibody QBEND10, which is directed against the haemopoietic stem cell related antigen CD34, in the immunohistochemical diagnosis of myelodysplastic syndrome in routinely processed bone marrow biopsy specimens.

Methods-581 formalin fixed, paraffin embedded trephine biopsy specimens of the iliac crest were immunostained with QBEND10 (avidin-biotin complex/ABC method). The number of CD34 + haemopoietic stem cells/blast cells (referred to hereafter as CD34 + cells) was determined in each case. The Wilcoxon test was used for statistical analysis.

Results-The following diagnostic categories were defined: (1) normal or reactive bone marrow $(n=356)$, (2) lymphoproliferative disorders, usually non-Hodgkin's lymphoma of low grade malignancy or multiple myeloma $(n=118)$, (3) myelodysplastic syndrome $(n=22)$, (4) acute leukaemia $(n=44)$, and (5) myeloproliferative diseases $(n=41)$. The average number of CD34 + cells was very low $(0 \cdot 2 / H P F)$ in normal and reactive bone marrow, in lymphoproliferative disorders and in the myelodysplastic syndrome subtypes RA and RARS. Myeloproliferative diseases showed an average of three CD34 + cells/HPF. However, the average number of CD34 + cells was significantly higher $(p<0.05)$ in the myelodysplastic syndrome subtypes RAEB and RAEB-T (8.7/HPF) and in acute leukaemia (including both myeloid and lymphoblastic leukaemia; 111· $7 /$ HPF).

Conclusions-QBEND10 is of value for the identification of RAEB and RAEB-T in routinely processed bone marrow biopsy specimens because it enables the detection of even small increases in the number of CD34 + cells.

(f Clin Pathol 1995;48:291-294)
\end{abstract}

Keywords: Acute leukaemia, bone marrow, CD34, immunohistochemistry, myelodysplasia.
The myelodysplastic syndromes have been classified by the French-American-British (FAB) cooperative group into five separate categories. ${ }^{1}$ The number of blast cells is an important factor here: it is usually low in refractory anaemia (RA), refractory anaemia with ringed sideroblasts (RARS), and chronic myelomonocytic leukaemia. ${ }^{2}$ By definition, it is increased in the subtypes "refractory anaemia with excess of blast cells" (RAEB) and "refractory anaemia with excess of blast cells in transformation" (RAEB-T). It may be difficult to define the subtype using routinely processed (formalin fixed, paraffin embedded) bone marrow biopsy specimens, especially when blood and bone marrow smears are not available to the haematopathologist for comparison. The pathognomonic ringed sideroblasts cannot be identified in routinely processed bone marrow biopsy specimens because mitochondrial iron deposits remain unstained by the Prussian blue stain. Various histopathological findings have been found to be associated to varying extents with myelodysplastic syndromes, for example abnormally localised immature myeloid precursor cells (the so called ALIP phenomenon), ${ }^{3}$ megakaryocyte atypia, especially an increase in micromegakaryocytes, ${ }^{4}$ and fibrosis ${ }^{5}$ and oed$\mathrm{ema}^{6}$ of the marrow stroma. These findings are all either non-specific (fibrosis, oedema) or

Table 1 Haematological diagnosis

\begin{tabular}{ll} 
Diagnosis & Number of cases \\
\hline (1) Normal bone marrow & 147 \\
(2) Reactive bone marrow & 209 \\
(3) Lymphoproliferative disorders & 118 \\
(4) Myelodysplastic syndromes & \\
RA & 4 \\
RARS & 7 \\
RAEB & 9 \\
RAEB-T & 2 \\
(5) Myeloproliferative diseases & 25 \\
Chronic myeloid leukaemia & 9 \\
Agnogenic myeloid metaplasia & 7 \\
Polycythaemia rubra vera & 27 \\
(6) Acute myeloid leukaemia & 17 \\
\hline
\end{tabular}

$\mathrm{RA}=$ refractory anaemia; $\mathrm{RARS}=\mathrm{RA}$ with ringed sideroblasts RAEB $=$ RA with excess blast cells; RAEB- $T=R A$ with excess blast cells in transformation. 


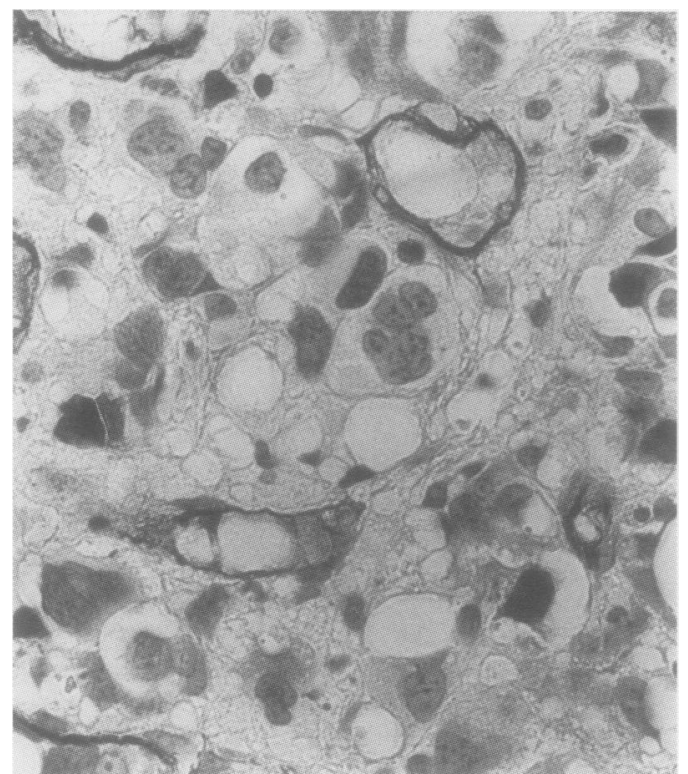

Figure 1 Megakaryocytic leukaemia. Diffuse infiltration of the bone marrow by atypical large megakaryocytes is shown. While there is strong immunostaining of the endothelial cells of dilated small blood vessels by QBEND10 (anti-CD34), the tumour cells remain completely unstained. QBEND10; ABC method; $\times 422$.

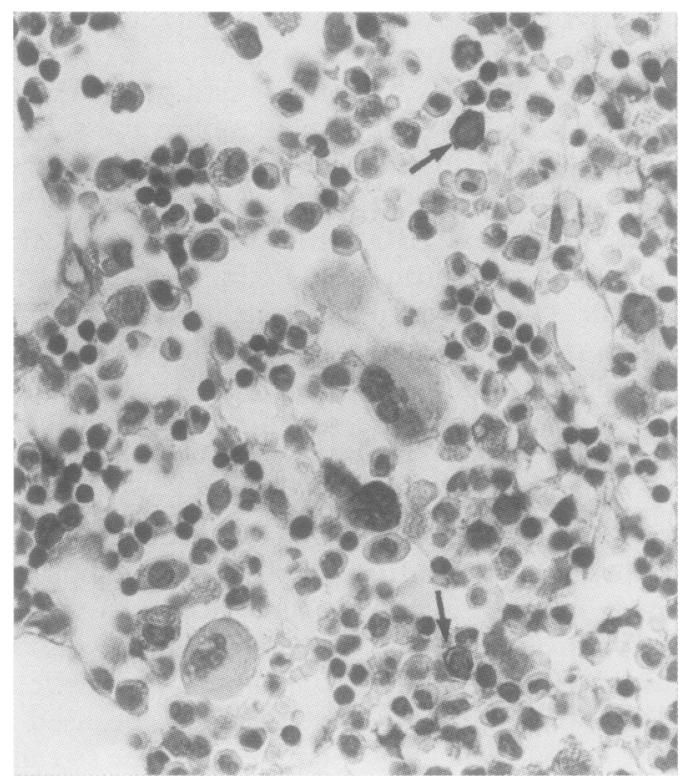

Figure 2 Normal human bone marrow. Immunostaining with QBEND10 (anti-CD34) produces annular (that is, specific) staining of a few loosely scattered, medium sized cells of lymphoid appearance, almost certainly pluripotent haemopoietic stem cells (arrows). Note the normal distribution of blood cell precursors. QBEND10; $A B C$ method; $\times 422$.

difficult to assess histologically (ALIP, micromegakaryocytes). Therefore we have looked for additional more specific and more easily reproducible findings that could be of value for identifying and subtyping myelodysplastic syndromes in bone marrow biopsy specimens. Immunohistochemical investigation of the bone marrow with an antibody directed against the haemopoietic stem cell related antigen CD34 proved to be of major diagnostic value.

\section{Methods}

All bone marrow specimens submitted to the Institute of Pathology, University of Tübingen,

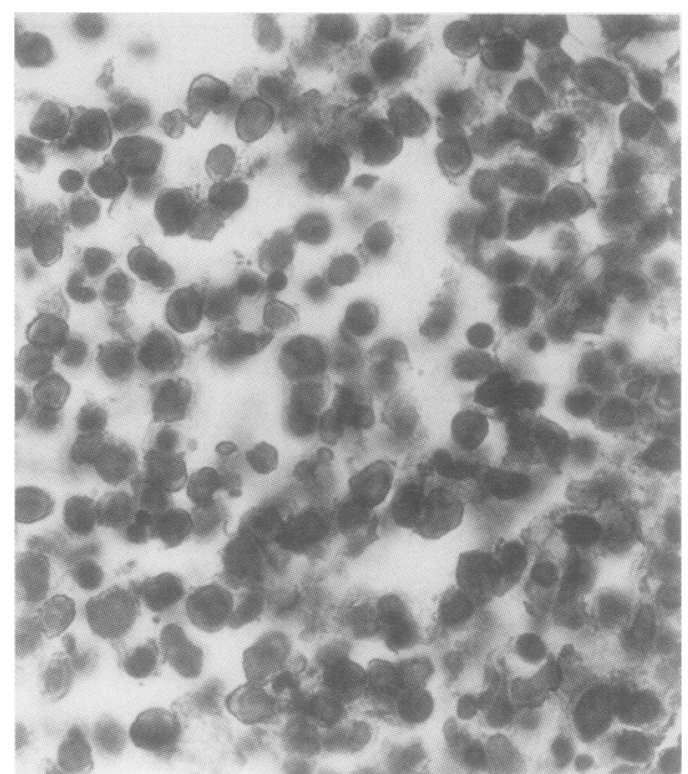

Figure 3 Myelodysplastic syndrome, subtype RAEB-T. Hypercellular bone marrow with a moderate increase in blast cells showing annular staining for CD34

(approximately 20-25\% of nucleated cells). QBEND10; $A B C$ method; $\times 600$.

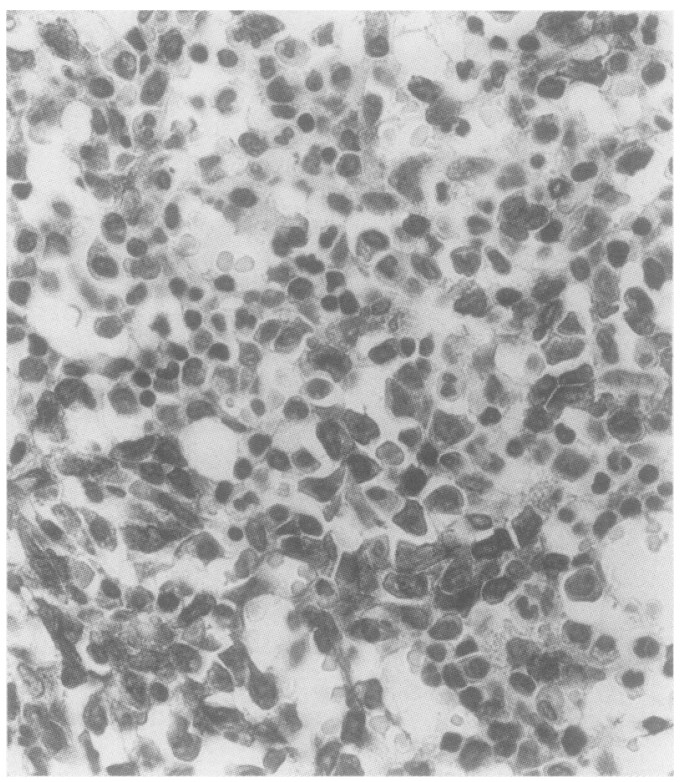

Figure 4 Acute myelomonocytic leukaemia. Hypercellular marrow with a marked increase in large blast cells. Many of the tumour cells are monocytoid in appearance, contain pleomorphic nuclei, and show annular staining for CD34. As is also seen in fig 3 there is a marked decrease in number of normal blood cell precursors. QBEND10; $A B C$ method; $\times 422$.

over a six month period from July to December 1993 , amounting to a total of 581 , were included in the study. Diagnosis (table 1) was based on histological evaluation of these specimens and, in the case of myelodysplastic syndromes and acute leukaemia, enzymecytochemical and immunocytological investigation of blood and bone marrow smears. All the specimens were taken from the iliac crest, fixed in $5 \%$ buffered neutral formalin for $24 \mathrm{~h}$, and embedded in paraffin wax. After mild decalcification in EDTA, ${ }^{7}$ sections were cut to $4 \mu \mathrm{m}$ thickness, rehydrated, and stained with haematoxylin and eosin, periodic acid-Schiff reaction, Giemsa, Gömöri’s silver impreg- 
nation, and naphthol AS-D chloroacetate esterase reaction. ${ }^{8}$ Immunohistochemical staining with the antibody QBEND10 (Dianova, Hamburg, Germany) was performed by the avidin-biotin-peroxidase complex method. ${ }^{9}$ QBEND10 is one of the few antibodies raised against the human haemopoietic stem cell related antigen CD34 that can be used on routinely processed biopsy specimens.

Blood vessel endothelial cells, which were always reactive with QBEND10, served as an internal positive control (fig 1). Only haemopoietic cells/blast cells with annular staining (referred to hereafter as CD34 + cells) were evaluated (figs 2, 3, and 4). Their average number per high power field (HPF) was determined in each case by assessment of at least $10 \mathrm{HPF}$ from representative areas of marrow. Their number was also estimated semiquantitatively on a four grade scale with the categories none, small, moderate, and large. The Wilcoxon test was used for statistical analysis.

\section{Results}

The results of the quantitative evaluation of CD34 + cells are summarised in table 2 . Normal and reactive bone marrow and marrow involved by lymphoproliferative disorders and the myelodysplastic syndrome subtypes RA and RARS usually contained at most very small numbers of CD34 + haemopoietic cells-on average about $0 \cdot 2 / \mathrm{HPF}$.

The myeloproliferative disorders, taken together, showed a considerably larger average number of $\mathrm{CD} 34+$ cells $(3 / \mathrm{HPF})$, but the difference was not statistically significant. Although the average in all the cases of agnogenic myeloid metaplasia and polycythaemia rubra vera was comparable to that in normal/reactive marrow, it was moderately increased in five of the 25 cases of chronic myeloid leukaemia. All these five patients were clinically in the accelerated phase of the disease but not in an overt blast crisis.

The number of CD34+ cells was significantly higher $(p<0.05)$ in the myelodysplastic syndrome subtypes RAEB and RAEB-T, amounting to $8 \cdot 7 / \mathrm{HPF}$. It was highest in acute leukaemia (both myeloid and lymphoid), in which it reached an average of nearly $112 / \mathrm{HPF}$, although about $50 \%$ of the specimens did not show any increase in CD34 expression.

Table 2 Quantitative evaluation of numbers of CD34+ haemopoietic cells/blast cells in normal, reactive, and neoplastic human bone marrow

\begin{tabular}{lrl} 
Diagnosis & Number of CD34+ cells/HPF & $p$ \\
\hline Normal $(\mathrm{n}=147)$ & $0 \cdot 20 \pm 0.34$ & \\
Reactive $(\mathrm{n}=209)$ & $0 \cdot 25 \pm 0.41$ & $\mathrm{NS}$ \\
LPD $(\mathrm{n}=118)$ & $0 \cdot 13 \pm 0.25$ & $\mathrm{NS}$ \\
MPD ( $\mathrm{n}=41)$ & $3.02 \pm 10 \cdot 44$ & $\mathrm{NS}$ \\
MDS $(\mathrm{n}=22)$ & $8 \cdot 68 \pm 18.86$ & $<0.04$ \\
AL $(\mathrm{n}=44)$ & $111.73 \pm 184.03$ & $<0.001$
\end{tabular}

LPD = lymphoproliferative disorders; $\mathrm{MPD}=$ myeloproliferative disorders; $\mathrm{MDS}=$ myelodysplastic syndromes; $\mathrm{AL}=$ acute leukaemias.
The results of the semiquantitative analysis are summarised in table 3. Moderate and large numbers of CD34 + blast cells were confined almost exclusively to the myelodysplastic subtypes RAEB and RAEB-T, acute leukaemia, and a small proportion of the cases of myeloproliferative disorder. Most of the specimens of normal or reactive marrow and marrow infiltrated by lymphoproliferative disorders or myelodysplastic syndrome subtypes $\mathrm{RA}$ and RARS contained only small numbers of CD34 + cells or none at all. However, four specimens of normal or reactive marrow (two derived from children with slight hypocellularity of the bone marrow but intact haemopoiesis) and one specimen with infiltration by non-Hodgkin's lymphoma of low grade malignancy showed a moderate increase in CD34 + haemopoietic progenitor cells.

\section{Discussion}

The expression of the glycoprotein CD34 is highly restricted to a crucial subset of haemopoietic progenitor cells and is found on $1-4 \%$ of human bone marrow cells. ${ }^{10}$ Little is known about its functional properties, but it was shown recently that monoclonal antibodies against $O$ sialoglycoprotease sensitive epitopes of CD34, (including QBEND10, which was also used in this study) induce actin polymerisation in CD34 + haemopoietic cells, with subsequent strongly enhanced cytoadhesiveness. ${ }^{11}$ CD34 expression declines progressively as the progenitor cells differentiate and become committed to particular lineages. ${ }^{12}$

The findings of this immunohistochemical study are well in accord with those of FACS analysis, which has shown a very low incidence of CD34 + haemopoietic cells in normal and reactive bone marrow. It is difficult to explain why CD34 + haemopoietic cells could not be detected immunohistochemically in a considerable proportion of our cases. It is possible that in routinely processed trephine specimens only the very immature (totipotent) haemopoietic stem cells with relatively strong expression of CD34 are immunostained, and the committed progenitor cells with reduced expression of CD34 remain unstained. This hypothesis is supported by the fact that the number of CD34-immunoreactive haemopoietic cells increases slightly in some cases after microwave treatment (our unpublished observations).

Table 3 Semiquantitative evaluation of numbers of CD34+ haemopoietic cells/blast cells in normal, reactive and neoplastic human bone marrow

\begin{tabular}{lllll} 
Diagnosis & 0 & + & ++ & +++ \\
\hline Normal $(\mathrm{n}=147)$ & $48 \%$ & $50 \%$ & $2 \%$ & 0 \\
Reactive $(\mathrm{n}=209)$ & $44 \%$ & $55 \%$ & $1 \%$ & 0 \\
LPD $(\mathrm{n}=118)$ & $52 \%$ & $47 \%$ & $1 \%$ & 0 \\
MPD $(\mathrm{n}=41)$ & $44 \%$ & $44 \%$ & $12 \%$ & 0 \\
MDS $(\mathrm{n}=22)$ & $23 \%$ & $41 \%$ & $27 \%$ & $9 \%$ \\
AL $(\mathrm{n}=44)$ & $27 \%$ & $23 \%$ & $14 \%$ & $36 \%$ \\
\hline
\end{tabular}

Number of immunostained cells: $0=$ none; $+=$ small $(<1 \%$ of nucleated cells); $++=$ moderate $(>1 \%$ and $<20 \%) ;+++=$ large $(>20 \%)$.

For abbreviations see table 2 . 
The most important result of our study is probably the finding that the application of QBEND10 on routinely processed bone marrow biopsy specimens enables identification of the myelodysplastic syndrome subtypes RAEB and RAEB-T, because the numbers of CD34+ blast cells here were significantly greater than in normal of reactive marrow. It must be emphasised that only these two subtypes showed a significant increase in CD34 + cells. The RA and RARS subtypes showed no such increase, as might be expected from the low blast cell count found in bone marrow smears in these subtypes. ${ }^{21314}$

One further conclusion concerning the myeloproliferative syndromes can be drawn from our immunohistological findings. Because an increase in CD $34+$ cells was noted in the accelerated phase of chronic myeloid leukaemia but not in chronic phase disease, immunostaining of trephine biopsy specimens with an appropriate antibody could be useful for identifying patients in the accelerated phase.

About a third of the cases of acute leukaemia, including leukaemias both of myeloid and of lymphoid origin, showed expression of CD34 by the majority of the blast cells. A similar frequency of CD34 expression in acute leukaemia was reported in a study in which a clear correlation between flow cytometric and immunohistological findings was also found in such cases. ${ }^{15}$ The expression of CD34 by the blast cells therefore does not allow identification of the cell lineage involved.

The authors thank Ms $\mathrm{H}$ Ableiter and Ms A Mall for excellent technical assistance and Dr M Ruck for help in preparation of the manuscript. This study was supported by a grant from the Else-Übelmesser-Stiftung, Tübingen, Germany.
1 Bennett JM, Catovsky D, Daniel MT, et al. Proposals for the classification of the myelodysplastic syndromes. $\mathrm{Br} \mathcal{F}$ Haematol 1982;51:189-99.

2 Vandermolen L, Rice L, Rose MA, Lynch EC. Ringed sideroblasts in primary myelodysplasia. Leukemic propensity and prognostic factors. Anch Intern Med 1988;148: pensity

3 Tricot G, Vlietinck R, Boogaerts MA, et al. Prognostic factors in the myelodysplastic syndromes: importance of initial data on peripheral blood counts, bone marrow cytology, trephine biopsy and chromosomal analysis. $\mathrm{Br} \mathcal{F}$ Haematol 1985;60:19-32.

4 Fox SB, Lorenzen J, Heryet A, Jones M, Gatter KC, Mason DY. Megakaryocytes in myelodysplasia: an immunohistochemical study on bone marrow trephines. Histopathology 1990;17:69-74.

5 Gottlieb CA, Maeda K, Hawley RC, Abraham JP. Myelodysplasia with bone marrow lymphocytosis and fibrosis mimicking recurrent Hodgkin's disease. Am $₹$ Clin Pathol 1989;91:6-11.

6 Thiele J. Pathologie der Präleukämie. Verh Dtsch Ges Path 1983;67:115-31.

7 Horny H-P, Kaiserling E. Lymphoid cells and tissue mast cells of bone marrow lesions in systemic mastocytosis: a histological and immunohistological study. Br $\mathcal{F}$ Haematol histological and imn

8 Leder L-D. Über die selektive fermentcytochemische Darstellung von neutrophilen myeloischen Zellen und Gewebsmastzellen im Paraffinschnitt. Klin Wochenschr 1964; 42:553.

9 Hsu S-M, Raine L, Fanger $H$. Use of avidin-biotin peroxidase complex (ABC) in immunoperoxidase techniques: a comparison between $\mathrm{ABC}$ and unlabelled antibody (PAP) procedures. F Histochem Crytochem 1981;29:57780 .

10 Silvestri F, Banavali S, Baccarani M, Preisler HD. The CD34 hemopoietic progenitor cell associated antigen: biology and clinical applications. Haematologica 1992;77: 265-72.

11 Majdic $O$, Stöckl J, Pickl W, et al. Signaling and induction of enhanced cytoadhesiveness via the hematopoietic pro-
genitor cell surface molecule CD34. Blood 1994;83:122634.

12 Simmons PJ, Torok-Storb B. CD34 expression by stromal precursors in normal adult bone marrow. Blood 1991;78: precursors

13 Oertel J, Kleiner S, Huhn D. Immunotyping of blasts in refractory anaemia with excess of blasts. Br $\mathcal{f}$ Haematol 1993;84:305-9.

14 Oertel J, Oertel B, Beyer J, Huhn D. CD34 immunotyping of blasts in myelodysplasia. Ann Hematol 1994;68:77-80.

15 Hanson CA, Ross CW, Schnitzer B. Anti-CD34 immunoperoxidase staining in paraffin sections of acute leukemia: comparison with flow cytometric immunophenotyping. Hum Pathol 1992;23:26-32. 